\title{
ARTIGOS
}

\section{AS ASPIRAÇÕES DOS APRENDIZES: DOUTORANDOS EM EDUCACÃ̃O NO BRASIL}

\author{
CAMILA FERREIRA DA SILVA' \\ MARIANA GAIO ALVES"
}

\section{RESUMO}

Refletir sobre os fenômenos educacionais não constitui exercício recente no contexto brasileiro. Porém os processos de autonomização e institucionalização de um espaço específico para pensar, investigar e formar novos quadros no âmbito estrito da Educação ganham materialidade na primeira metade do século XX e influenciam o ganho paulatino de pujança da área. Com o intuito de compreender as relações entre as aspirações dos doutorandos em Educação no Brasil e o próprio desenvolvimento dessa área do conhecimento, por meio da análise de 455 questionários respondidos pelos estudantes, o presente artigo situa-se no debate de influência bourdieusiana acerca da correspondência entre campo e habitus. O estudo revelou o poder das relações educativas nos processos de constituição e compartilhamento de um habitus próprio desse espaço acadêmico, de reprodução dos seus quadros e ainda de construção das aspirações dos doutorandos.

EDUCAÇÃO • DOUTORAMENTO • ASPIRAÇÃO • DESENVOLVIMENTO PROFISSIONAL

\section{APPRENTICES' ASPIRATIONS: DOCTORAL STUDENTS IN EDUCATION IN BRAZIL}

\section{ABSTRACT}

Reflecting about the educational phenomena is not a novelty in the Brazilian context. However, the empowerment and institutionalization processes of a specific space to think, investigate and train new staff in the strict context of education gain materiality in the first half of the twentieth century and influence the gradual increase of importance of the area. In order to understand the relationships

Unidade de Investigação Educação e Desenvolvimento - UIED/FCT - Universidade Nova de Lisboa - UNL Lisboa, Portugal; ferreira. camilasilva@gmail.com between the aspirations of the doctoral students in the area of Education in Brazil and the development of this area of knowledge, this article, through the analysis of 455 questionnaires answered by students, discusses Bourdieu's influence on the correspondence between field and habitus. The study revealed the power of educational relations in the processes of constitution and sharing of a habitus of this academic space, as well as in the processes of reproduction of their cadres and of construction of doctoral students' aspirations.

EDUCATION • DOCTORAL DEGREES • ASPIRATION • VOCATIONAL DEVELOPMENT 
RÉSUMÉ

Réfléchir sur les phénomènes d'éducation n'est pas une nouveauté dans le contexte brésilien. Toutefois, les processus d'autonomisation et d'institutionnalisation d'un espace spécifique pour penser, mener des recherches et former de nouveaux cadres dans le domaine restreint de l'éducation ont pris de l'importance a partir de la première moitié du XXe siècle et ont progressivement contribué au prestige peu de ce champ. Afin de mieux comprendre les rapports entre les aspirations des doctorants en éducation au Brésil et le développement de ce domaine de connaissance, cet article, par moyen de l'analyse de 455 questionnaires répondus par les étudiants, se situe dans une perspective bourdieusienne concernant la correspondance entre champ et habitus. L'étude a révélé la puissance des relations éducatives dans les processus de mise en place et de partage d'un habitus propre à cet espace académique, ainsi que dans ceux de reproduction de ses cadres et de construction des aspirations des doctorants.

EDUCATION • DOCTORAT • ASPIRATION • DÉVELOPPEMENT PROFESSIONNEL

\section{LAS ASPIRACIONES DE LOS APRENDICES: DOCTORANDOS EN EDUCACIÓN EN BRASIL \\ RESUMEN}

La reflexión sobre los fenómenos educativos no constituye un ejercicio reciente en el contexto brasileño. Sin embargo, los procesos de autonomización e institucionalización de un espacio específico para pensar, investigar y formar nuevos cuadros en el ámbito estricto de la Educación se materializaron en la primera mitad del siglo XX e influenciaron el crecimiento paulatino del vigor del área. Con el fin de comprender las relaciones entre las aspiraciones de los doctorandos en Educación en Brasil y el propio desarrollo de esa área del conocimiento, a través del análisis de 455 cuestionarios respondidos por los estudiantes, el presente artículo se sitúa en el debate de influencia bourdieusiana acerca de la correspondencia entre campo $y$ habitus. El estudio reveló el poder de las relaciones educativas en los procesos de constitución y del compartir un habitus propio de ese espacio académico, de reproducción de sus cuadros y también de construcción de las aspiraciones de los doctorandos. 
OMAR O FAZER CIENTÍFICO NA CONTEMPORANEIDADE COMO UMA PRÁTICA SOCIAL permite-nos compreender tanto as relações sociais que estão na sua constituição quanto aquelas que são construídas a partir da prática em questão (BOURDIEU, 2008). Tais relações são, por sua vez, reveladoras de um conjunto de agentes, disposições, posições, instituições e bens culturais que compõem [e são compostos por] o que chamaremos aqui de campo acadêmico - esse termo refere-se ao uso de um aparato institucional, normalmente assegurado pelo Estado e amplamente reconhecido pela sociedade, que garante a produção e a circulação de produtos acadêmicos (HEY, 2008). Nesse sentido, o exercício de objetivar o campo que tem como função social a objetivação do mundo em suas mais diferentes facetas passa necessariamente pela compreensão das relações supracitadas e, sobretudo, pela clareza de que tal exercício poderia ser realizado de formas completamente diversas, as quais seriam capazes de fazer emergir retratos também diversos desse espaço social.

Dentre essas diversas formas, a investigação que originou este artigo elencou a área da Educação no Brasil como um caso exemplificativo das mais diversas questões que circundam o mundo universitário neste país: entre a generalidade da prática científica e as especificidades de uma área do conhecimento, emergem componentes relacionadas ao desenvolvimento de um espaço particular, o espaço de cada domínio, e suas condições sociais de relativa autonomização. 
Nesse sentido, perscrutar as propriedades - sociais, históricas, científicas, bem como a sua doxa (BOURDIEU, 1996) - constituintes do espaço acadêmico específico da Educação no contexto brasileiro constituiu esforço primeiro para o debate que levantamos aqui. O objetivo do texto consiste em compreender as relações entre as aspirações dos doutorandos e o próprio desenvolvimento da área da Educação: o nexo entre os conceitos bourdieusianos de campo e habitus nos permitem analisar a constituição das expectativas acadêmicas e profissionais dos estudantes de determinada área em uma relação dialética com a constituição e desenvolvimento da área na qual esses estudantes estão inseridos. No plano da operacionalização metodológica do estudo, destacamos a combinação entre as abordagens quantitativa e qualitativa, inserida na perspectiva da Sociologia compreensiva, e que faz uso, de um lado, de revisão de literatura para a releitura sócio-histórica e, de outro, da aplicação de questionário on-line com 455 estudantes de doutorado em programas de pós-graduação em Educação para o mapeamento de suas características e pretensões.

Ademais, no que tange à sistematização da exposição argumentativa, o artigo divide-se em três seções, nomeadamente: o caráter educativo das relações sociais que sustentam os campos sociais ganha relevo na primeira parte, com o intuito de demonstrar como a construção e incorporação de disposições são processos que implicam uma prática educativa e como tal prática é salutar para a reprodução de um campo social; já no segundo momento do texto, ocupamo-nos da releitura sócio-histórica, supracitada, acerca dos percursos de institucionalização e consolidação da Educação como campo acadêmico específico no interior da estrutura universitária brasileira; e, por fim, a terceira e última parte do artigo é marcada pela apresentação e análise das aspirações dos doutorandos que participaram da investigação.

\section{AS RELAÇÕES EDUCACIONAIS QUE SUSTENTAM OS CAMPOS SOCIAIS}

A sociologia do campo intelectual francês, bem como a sociologia dos campos da produção de bens simbólicos, empreendidas por Pierre Bourdieu (1990), são capazes de revelar as homologias estruturais e funcionais que existem entre os diferentes campos sociais. Essa premissa respalda a nossa compreensão do campo científico e, dessa forma, as relações entre campo, habitus e seus agentes ganham relevo, afinal, 
um filósofo com questões próprias dos geógrafos) e que não são percebidos por quem não foi formado para entrar neste campo (cada categoria de interesse implica a indiferença em relação a outros interesses, a outros investimentos, destinados assim a serem percebidos como absurdos, insensatos, ou nobres, desinteressados). Para que um campo funcione, é preciso que haja objetos de disputas e pessoas prontas a disputar o jogo dotadas de habitus que impliquem o conhecimento das leis imanentes do jogo, dos objetos de disputas, etc. (BOURDIEU, 1983, p. 89)

Nenhuma das propriedades do campo científico foi gerada de forma apriorística; elas possuem valor somente nesse universo de referência, nas lutas no interior do espaço acadêmico. Dessa forma, o que seria essa "formação para entrar no campo"? E, ainda, como as pessoas ficam "prontas" para disputar o jogo em questão? Esses questionamentos nos colocam diante da problemática das possibilidades de investimento e de obtenção de sucesso, a partir de tais investimentos e da consequente posição dos agentes dispostos no campo científico. O conhecimento das leis imanentes do jogo, como coloca Bourdieu (1983), depende necessariamente de uma experiência de aprendizagem das lógicas e das práticas esperadas e respeitáveis pelos agentes que compõem o campo. Tal experiência, por seu turno, coloca em relação educativa agentes que ocupam posições completamente distintas no espaço em questão e que não necessariamente estabelecem um vínculo formal de docente-estudante ou mesmo de orientação.

Nesse sentido, fazer parte dos espaços contemporâneos de desenvolvimento de investigações - com especial destaque para as instituições de ensino superior, mas sem esquecer de assinalar instituições de financiamento, associações de pesquisa, etc. -, mesmo que estejamos a falar de um estudante que acaba de entrar na universidade, implica educar-se não somente com base nos currículos oficiais e nos saberes técnicos de sua futura profissão. Isso considerando que a pedagogia do silêncio comunica a doxa (opinião consensual) e o nomos (leis gerais) da área do conhecimento na qual o estudante acabou de ser inserido (BOURDIEU; EAGLETON, 1996; THIRY-CHERQUES, 2006). ${ }^{1}$ Mais do que os conhecimentos específicos de uma área, apresentados e discutidos

O oxímoro a que recorremos nesta passagem possui relação com o conceito de "currículo oculto" (APPLE, 1994; SILVA 1992; SANTOMÉ 1994 PERRENOUD, 1996), posto que nos referimos a um conjunto de saberes, valores e comportamentos que apesar de não comporem o currículo oficial, emergem no cotidiano das práticas. em sala de aula, a socialização que ocorre no ambiente universitário permite que os partícipes compreendam aquilo que não é necessariamente declarado, mas acaba por ser externalizado por meio das relações estabelecidas nesse ambiente: as vestes, os gestos, a fala, o que é tacitamente permitido ou proibido de se fazer, enfim, toda uma economia comportamental é partilhada no cotidiano acadêmico e internalizada a partir de processos educativos. Pode-se dizer que as duas frentes educativas aqui apontadas - uma explícita e curricular e uma outra mais 
silenciosa - proporcionam um entendimento das lógicas que regem esse campo, bem como uma conformidade das práticas às regras do jogo acadêmico.

Ao abordar a questão do ensino de um ofício, ou de uma arte nos termos de Durkheim, Bourdieu (2011) demonstra que, tanto nas sociedades sem escrita e sem escola, quanto naquelas com escola, existem numerosos modos de pensamento e ação, os quais são transmitidos de prática a prática no contato direto e doradouro entre aquele que ensina e aquele que aprende, o que o autor chama de "faz como eu”. No âmbito da própria formação para o universo científico, Bourdieu (2011) constata que os próprios historiadores e filósofos das ciências, e também os cientistas de modo geral, têm verificado que parte significativa da profissão de cientista é obtida por meios de aquisição inteiramente práticos. O habitus científico pode ser entendido, pois, como um modus operandi que segue as normas da ciência e é capaz de gerar as condutas adequadas para os respectivos momentos, essa espécie de sentido do jogo científico e sua relação com o senso prático não pode ser concebida como uma reação mecânica pura e simplesmente (PERRENOUD et al., 2001). Como esquema gerador das ações, o habitus não deve ser tomado como uma disposição estática, posto que é durável, mas funciona como orientação no âmbito da relação entre a experiência passada de classificação e uma determinada situação.

Isto posto, pode-se afirmar que a constituição do habitus lobriga-se a partir do modo como as estruturas externas ao indivíduo e ligadas a determinado campo social são internalizadas pelo resultado das experiências de socialização às quais o indivíduo é submetido (BOURDIEU, 1977; MANGI, 2012). Cada campo social possui uma relativa autonomia, quando tomado em perspectiva relacional com outros campos sociais, e é caracterizado pela construção de especificidades que o distinguem; tais especificidades manifestam-se nos seus próprios agentes, na sua própria lógica de ação e funcionamento, nas suas próprias formas de capital e podem ser apreendidas pela própria história do campo. Esse debate acaba por ratificar a necessidade de compreendermos a noção de campo em sua interdependência e relação a outras noções (tais como habitus e capital) e, dessa forma, possibilita-nos compreender a própria obra bourdieusiana em função da posição que o sociólogo francês ocupou no universo acadêmico no qual esteve inserido. ${ }^{2}$

No que tange ao conceito de campo, além da necessidade de compreendê-lo em relação a outros conceitos, Catani (2013) elenca elementos importantes para caracterizá-lo, a saber: a relação entre microcosmo (campo) e macrocosmo (espaço social global); as especificidades das regras do jogo de cada campo; as posições em disputa e, consequentemente, as lutas entre os agentes e suas estratégias; o capital desigualmente distribuído dentro do campo e, em função disso, a existência de vida e obra de Bourdieu, recomendamos a leitura de Catani (2013). O esforço relacional do autor em questão acaba por auxiliar no mapeamento da gênese do conceito de campo no âmbito do empreendimento científico de Bourdieu. 
dominantes e dominados; a cumplicidade objetiva entre os agentes; o habitus legítimo de cada campo; e a autonomia relativa de cada campo. Esses elementos contribuem para um esboço mais generalista em torno da noção de campo ao passo que salientam, de um lado, o caráter relacional com o qual deve-se olhar para quaisquer espaços sociais e, de outro, a necessidade de especificação.

Nesse movimento de situar um campo social, no coletivo e na singularidade concomitantemente, emerge o debate acerca da inseparabilidade entre teoria e empiria no exercício de objetivação: capturar as lógicas do mundo social, mesmo que estejamos a falar da lógica mais profana, significa aprofundar, na particularidade de uma realidade empírica, um caso particular do possível, historicamente datado e situado (BOURDIEU, 1996). A relação dialética entre todo e parte configura elemento crucial para a clareza não somente das relações entre os mais diversos campos sociais, mas também dos traços comuns a todos eles. É essa clareza que nos permite tratar do campo universitário a partir do arranjo coletivo-singular: o campo universitário, regido por suas lutas próprias, pode ser entendido como qualquer outro campo social, uma vez que se constitui em um espaço de embates para determinar "as condições e os critérios de pertencimento e de hierarquia legítimos" (BOURDIEU, 1984, p. 32). Desse modo, a compreensão deste campo em específico requer um esforço mais amplo e relacional que vai da observação do processo de autonomização da esfera cultural até a possibilidade de criação de um mercado de relações de produção e consumo (FERREIRA; BRITTO, 1994) no âmbito da academia no Brasil.

A fórmula de Blaise Pascal, citada e um tanto deformada por Bourdieu, sintetiza esta discussão: "O mundo me contém e me engole como um ponto, mas eu o contenho" (BOURDIEU, 1996, p. 27). A perspectiva relacional nos permite enxergar tanto os campos sociais em relação uns com os outros quanto os próprios agentes que os compõem em relação com os outros agentes e em relação com os campos nos quais transitam e ainda com aqueles que influenciam sua trajetória social. Nessa perspectiva, Catani (2013) caracteriza o campo universitário brasileiro como um espaço de lutas - desde o aparato institucional assegurado pelo Estado até os próprios pesquisadores, passando pelos ministérios, pelas agências de fomento e demais órgãos que compõem esse universo -, demonstrando não apenas sua concretude, mas também as lutas que o marcam e as possibilidades analíticas que emergem da teoria dos campos de Bourdieu. Sobre isto, o autor afirma: “O espaço universitário é real não apenas pela sua estrutura, mas também porque esta se vê incorporada nas disposições dos agentes” (CATANI, 2013, p. 77).

Seja no campo universitário brasileiro, como indicou Catani (2013), seja em qualquer outro campo, essa incorporação de disposições acaba por estabelecer limites estruturais para a ação, por um lado, e, por 
outro lado, gera percepções, aspirações e práticas que correspondem às propriedades estruturantes do processo de socialização (MANGI, 2012). Essas características fulcrais do habitus explicam a terminologia "estruturas estruturadas" e "estruturas estruturantes" e permitem-nos ratificar que os processos educacionais experienciados pelos agentes no sentido de apreender as lógicas do campo operam, para além da aprendizagem dessas lógicas, uma formação disposicional do real. Tal formação, ou o habitus propriamente dito, acaba por se manifestar em três dimensões, por meio: dos valores, dos costumes, da ética (Ethos); da estrutura corporal, do corpo biológico socializado, da ação social, da prática concreta (Héxis); e ainda por meio da estrutura mental, das ideias, do imaginário (Eidos) (BOURDIEU, 2001; MEUCCI, 2009).

Entre o todo e a parte, entre um conjunto de campos sociais e a especificidade de um determinado campo social, uma das características que atravessa todos os espaços sociais consiste justamente nos processos educativos como um dos sustentáculos de sua existência e reprodução ao longo dos anos. Tratamos de esclarecer, no início deste tópico, como os entrantes e menos experientes aprendem as lógicas que regem um campo, seja por meio de uma aprendizagem formal, seja sobretudo por meio das experiências práticas e silenciosas que marcam o cotidiano; logo depois, preocupamo-nos em mostrar como um campo não pode ser tomado em si mesmo quando buscamos compreendê-lo e como, em função disso, existem elementos comuns aos diferentes campos sociais; e brevemente coadunamos essas duas frentes para demonstrar como a inseparabilidade entre campo, habitus (e outros constructos supracitados) é indispensável para compreender as relações entre os agentes e o campo.

Os processos concomitantes de incorporação de disposições e de construção de percepções, aspirações, práticas, etc. referem-se aos agentes; contudo, dizem respeito também ao campo social no qual esse agente encontra-se inserido, isso porque a constituição de um habitus específico e os processos educacionais que a permitem são condições sine qua non para a continuidade de um campo social qualquer. Outrossim, há sempre relações educativas que permitem que os mais novos ou menos experientes compreendam, participem e reproduzam a lógica do jogo que rege determinado espaço social - por este ângulo, podemos afirmar que, até mesmo para contestar essa lógica, os agentes precisam conhecê-la profundamente. Em nível geral, o habitus e a continuidade de um campo social advêm e dependem de processos educacionais; em nível do campo acadêmico, o mesmo princípio se aplica e, por isso, pesquisadores estabelecidos, outsiders e estudantes aspirantes estão em relação educativa (para além de outros tipos de relações) uns com os outros. 


\section{EDUCAÇÃO COMO ESPAÇO ACADÊMICO NO BRASIL: BREVES QUESTÕES SOBRE INSTITUCIONALIZAÇÃO E CONSOLIDAÇÃO}

As muitas formas de abordar a história da pesquisa em Educação no Brasil demonstram as dificuldades que os pesquisadores vêm encontrando para determinar marcos cronológicos, bem como maneiras para caracterizar o percurso em questão. Alguns trabalhos já bastante conhecidos, tais como Gouveia (1971), Saviani e Goldberg (1976), Goergen (1986), Warde (1990), Cunha (1991), e Campos e Fávero (1994), demonstram a preocupação dos pesquisadores brasileiros em objetivar a própria pesquisa desenvolvida na área da Educação. Guardadas as especificidades de abordagens e os dissensos que esses pesquisadores apresentam quando lidos em relação uns com os outros, dois elementos se destacam a partir dessa objetivação: primeiro, o movimento de autorreflexão que esses trabalhos inauguram no âmbito da área disciplinar da Educação; segundo, um certo consenso no que diz respeito ao padrão da produção científica, o qual nos permite constatar a existência de duas grandes fases, antes e depois da criação dos programas de pós-graduação em Educação.

Sobre o primeiro elemento, há que se reconhecer que tal movipioneiros já citados anteriormente, destacamos alguns estudos que se preocuparam em objetivar áreas específicas da Educação no Brasil Fiorentini et al. (2002) Gatti (2002), Costa e Silva (2003), Cury (2008) Bittar (2009), Carvalho (2011) e Frigotto (2011)

4

O exercício de autorreflexão do fazer científico atravessa todas as áreas do conhecimento. Autores trazem à tona reflexões que vão desde as epistemologias, do ofício de cientista ate questões teórico-metodológicas, a exemplo de Kant (1999), Durkheim (1999), Bloch (2001) Bourdieu, Chamboredon e Passeron (2002)

Aparecida Joly Gouveia (1971) apresenta três principais fases na evolução da pesquisa em Educação no Brasil, nomeadamente: a fase inaugural com o Inep, a partir de 1938; seguida da criação do Centro Brasileiro e dos Centros Regionais de Pesquisa em 1956; e, por fim, período compreendido entre 1964-1971. mento originou um tipo de trabalho que vem irradiando-se por muitas linhas que compõem a área da Educação ${ }^{3}$ e possibilitando um conhecimento cada vez mais aprofundado acerca das condições de produção da própria investigação educacional. ${ }^{4}$ No que se refere ao segundo elemento, faz-se mister para este artigo a discussão pormenorizada em torno das suas fases de desenvolvimento, isso porque, se a literatura aponta para um consenso relativo à criação da pós-graduação como um marco significativo e divisor do padrão de produção na área educacional, o mesmo não se dá quando o tema é justamente a trajetória que marca esta área no período anterior à década de 1960.

Marisa Bittar (2009), ao afirmar que a pesquisa em Educação no Brasil começara com a fundação do Instituto Nacional de Estudos Pedagógicos - Inep -, em 1938, esclarece, pois, que a investigação educacional antecede a criação dos programas de pós-graduação nessa área na metade da década de 1960. Esse pressuposto defendido pela autora em questão, e ancorado em análise já clássica de Aparecida Joly Gouveia (1971), ${ }^{5}$ constitui, de um lado, salutar referência no sentido de compreender que a pesquisa educacional não possui sua história completamente conectada com a instituição universitária brasileira. Porém, por outro lado, revela-se incompleto na medida em que se limita às questões institucionais, enquanto toma o Inep como marco de sua gênese em detrimento de uma ancestralidade que antecede esse período de institucionalização da realização da pesquisa nessa área.

Campos e Fávero (1994) chamam atenção para essa questão ao afirmarem que, antes da pós-graduação, a investigação educacional era 
realizada de forma "mais sistemática" em centros de pesquisa ligados ao Inep. E, nesse sentido, esses autores ultrapassam a leitura puramente corporativa, uma vez que compreendem que, mesmo antes da formalização de espaços específicos para a realização de investigações em Educação e mesmo na ausência de sistematização, a pesquisa em Educação antecede a própria fundação do Inep. É exatamente sobre a noção processual que ampara o "antes e depois" da institucionalização da investigação educacional no Brasil que nos debruçaremos neste momento.

Luiz Antonio Cunha (1978), mesmo concordando com a periodização proposta por Gouveia (1971), acrescenta dois elementos cruciais ao debate: o primeiro é relacionado com o marco inicial das atividades de investigação educacional; e o segundo, à implementação dos cursos de pós-graduação. Mais tarde, trataremos da ruptura provocada pela pós-graduação em Educação, posto que, neste momento, o primeiro elemento é determinante para o olhar que estamos a lançar para o transcruso brasileiro. Para Cunha (1978), alguns anos antes da criação do Inep, já seria possível registrar a introdução de um serviço de teses no Departamento de Educação da Prefeitura do Distrito Federal, por Anísio Teixeira, ${ }^{6}$ em 1932, como um primeiro esforço no sentido de institucionalização (GOERGEN, 1986). Além disso, e ainda a reboque do cargo de Anísio Teixeira em Brasília, a curta experiência da criação da Universidade do Distrito Federal - UDF -, pelo decreto municipal n. 5.513, de 1935, também é exemplificativa desse esforço, pois era composta por cinco escolas, dentre as quais estava a Escola de Educação (além das de Ciências, Economia e Direito, Filosofia e Instituto de Artes) (FÁVERO, 2004). ${ }^{7}$

O que une as experiências que antecederam a criação do Inep (seja na Associação Brasileira de Educação - ABE -, seja no esforço de Anísio Teixeira e de outros intelectuais da época, como Lourenço Filho, Fernando de Azevedo, etc.) é precisamente o caráter embrionário de união. Estamos a falar de união dos sujeitos que pensavam a Educação em grupos mais ou menos coesos capazes de comungar e debater ideias, investigações e até ideais que dialogavam, ao mesmo tempo, com o âmbito do ensino, bem como com a esfera da política educacional brasileira mais ampla. União essa que, em períodos anteriores, era certamente mais difícil de se concretizar dentro do espaço de possibilidades revelado pelas pesquisas desenvolvidas nas Escolas Normais em funcionamento no país e em trabalhos residuais e esporádicos de intelectuais e políticos de áreas diversas com preocupação em auxiliar o planejamento e o processo educativos (ALVARENGA, 1996). Esse movimento, que foi da dispersão à união em torno de uma área específica, encontra terreno fértil a partir dos anos de 1930, em meio a mudanças profundas na sociedade brasileira - estamos a falar dos processos sociais que desembocaram

6

Para um aprofundamento acerca do papel de Anísio Teixeira nesse contexto, consultar Leão (1960) e Fávero (2008)

7 Ferreira (2008) aponta ainda o papel de Lourenço Filho, também no início da década de 1930, na criação do Serviço de Estatística e Arquivo da Diretoria Geral da Instrução Pública do Estado de São Paulo como mais um elemento significativo que antecede e possibilita a criação do Inep anos mais tarde. 
numa modernização centralizadora no âmbito do chamado Estado Novo (1937-1945).

As iniciativas intervencionistas do Estado Novo em setores distintos da vida nacional, como demonstrou Ianni (1971), não demoram a verificar-se na área da Educação: a criação do Inep, em 1938, constitui, portanto, um evento que se insere em uma longa série de medidas que foram sendo tomadas pelo Estado brasileiro com o intento de afirmar-se como ente responsável pela educação diante da sociedade. A institucionalização da pesquisa educacional, por meio do Inep, conjugada com o financiamento do governo federal para a realização de tais investigações, operou uma ruptura significativa no modus operandi e no lugar social que a pesquisa nessa área vai passar a ocupar na sociedade brasileira. Gouveia (1971), em função dessa ruptura, toma o Inep como marco inicial da pesquisa em Educação no Brasil. Ademais, esse amplo processo de mudanças (que vai desde a institucionalização e o fomento e deságua na valorização da área de investigação) acabou por permitir que a Educação fosse transformada em um polo bastante atrativo para pesquisadores oriundos de áreas distintas. Essa atração de pessoal para o Inep vai ganhar mais expressividade a partir da segunda metade da década de 1950, quando da criação do Centro Brasileiro de Pesquisas Educacionais - CBPE - e dos Centros Regionais de Pesquisas Educacionais - CRPEs.

Durante os anos 1950 e 1960, o CBPE reuniu educadores e cientistas sociais em um projeto ambicioso que tinha como metas prioritárias promover o desenvolvimento de pesquisas sobre Educação, com a finalidade de subsidiar as políticas públicas do setor implementadas no Brasil (XAVIER, 1999). Baseado na periodização de Gouveia (1971), Guiomar Namo de Mello (1983) ratifica que a segunda fase de desenvolvimento da pesquisa educacional no país encontra sua gênese na criação dos centros brasileiro e regionais e possui como marco a substituição da ênfase nos estudos psicológicos pela preocupação com estudos sociológicos. ${ }^{8}$ No intento de mapear as características dos períodos de desenvolvimento da pesquisa educacional no Brasil, Bittar (2009) acrescenta duas iniciativas paralelas aos centros de pesquisa do Inep e a essa denominada segunda fase, que exemplificam a ampliação da área e uma certa diversidade já se desenhando no horizonte da investigação educacional no país, nome-

Costa e Silva (2003) apontam alguns dos nomes que foram atraídos pelo CBPE: Gilberto Freyre Thales de Azevedo Fernando Henrique Cardoso Octávio lanni e Carolina Bori. Nomes que não necessariamente tinham um interesse de pesquisa pela educação, mas que foram atraídos pela possibilidade de financiamento. adamente: de um lado, os estudos desenvolvidos na Universidade de São Paulo - USP - e nas faculdades de Filosofia do interior do estado de São Paulo, lideradas por Laerte Ramos de Carvalho, cujo grupo de pesquisa articulara-se em torno da cátedra de História e Filosofia da Educação; e, de outro lado, a nascente obra de Paulo Freire, que não se enquadraria no padrão do Inep, tampouco no da pós-graduação em Educação que marca o próximo momento da pesquisa educacional. Tais iniciativas expressam as dificuldades no exercício de periodização e já 
apontam a diversidade de frentes de investigação que comporão a área da Educação mais tarde.

Uma conjuntura desfavorável é responsável pelo enfraquecimento do CBPE e do Inep na década de 1960. Pode-se esboçar tal conjuntura pelas seguintes circunstâncias: uma crise financeira acarretada pela diminuição de verbas destinadas ao CBPE; a derrota dos jovens idealistas sociólogos (liderados por Florestan Fernandes e Darcy Ribeiro, que estabeleceram diálogo com o CBPE), em 1961, com a Lei de Diretrizes e Bases da Educação Nacional - LDB; e ainda o golpe militar de 1964. Esses constituíram fatores determinantes para a desarticulação desse centro, que se tornou símbolo do impulso que promoveu nas pesquisas educacionais no país. Apesar da curta existência, há que assinalar que os centros de pesquisas educacionais do Inep fizeram parte de um contexto de estímulo ao desenvolvimento de conhecimento científico e técnico no âmbito da Educação e, nesse sentido: contribuíram, de um lado, para o processo de institucionalização e de composição de um grupo específico de agentes que se preocupavam em pensar os fenômenos educacionais; e, por outro lado, ofereceram interpretações significativas para a realidade educacional brasileira, as quais influenciaram o pensamento pedagógico e as políticas do Estado (FERREIRA, 2008).

Mais uma ditadura, desta vez a ditadura militar (que no Brasil se estabeleceu entre 1964 e 1985), relaciona-se com um período de ruptura importante na história da pesquisa educacional brasileira, período esse indicativo do alcance das ações de agrupamento ou institucionalização da prática da investigação dessa área, experienciadas nas décadas anteriores. Estamos a falar em alcance porque, com essa chave analítica, é possível compreender as relações históricas e de dependência no espaço dos possíveis que a criação dos programas de pós-graduação em Educação, a partir de 1965, estabelece com os CBPE e CRPEs, com o Inep e com as demais experiências que a antecederam. A década de 1960 é marcada pela expansão dos quadros das universidades, com a emergência de grupos de pesquisa e a implementação da pós-graduação sob forma regulamentada em nível nacional (GATTI, 1983). Essa configuração, assinalada pela ambiguidade da expansão do ensino superior no contexto ditatorial, denuncia, na verdade, uma "modernização autoritária”, nos termos de Motta (2014). Tal modernização foi responsável: pelo aumento significativo do número de universidades federais, bem como pela expansão do corpo docente e ainda pelo incremento do número de estudantes (MOTTA, 2014).

No âmbito restrito da área da pesquisa educacional, a criação da pós-graduação em Educação, com a Pontifícia Universidade Católica do Rio de Janeiro - PUC-RJ - em 1965, insere-se no contexto mais geral de expansão do ensino superior no interior do regime militar; 9 porém, não se pode compreender a gênese da pós-graduação dessa área somente 9 Cunha (1991) lembra que o nascimento dos programas de pós-graduação se deu em um momento de expansão da graduação. 
com base nas decisões do Estado sobre as instituições de ensino superior do país. Evidentemente, essa expansão constituiu uma condição bastante relevante para a concretização da pós-graduação nessa área, mas é necessário reconhecer que os esforços e as experiências que antecederam esse momento também acabaram por transformar-se em condições de realização para o aparato institucional - de recursos humanos, de espaços de diálogos e de disseminação da produção - necessário para a institucionalização da pesquisa em Educação nas universidades brasileiras por meio dos programas de pós-graduação. ${ }^{10}$

Gouveia (1971) aponta uma terceira fase da pesquisa em Educação no Brasil, entre 1964 e 1971, englobando necessariamente a criação dos programas de pós-graduação: segundo a autora, predominaram estudos de natureza econômica, fomentados por órgãos federais e internacionais de financiamento. Mesmo com as discordâncias entre a periodização do desenvolvimento da pesquisa educacional no Brasil (GOUVEIA, 1971; CUNHA, 1978; BITTAR, 2009), existe um consenso dentre os pesquisadores acerca do impacto que a pós-graduação causou no percurso de desen-

Sobre essa relação entre 0 contexto da ditadura militar e a instauração da pós- graduação em Educação no Brasil, vale a pena destaca o depoimento de Savian (2001) O autor denomina os primeiros anos da pós-graduação nessa área de anos heróicos" em função das condições precárias para a implementação dos programas.

11

o que não isentou a área de sofrer críticas sobre a qualidade da sua produção (MELLO, 1983; WARDE 1990; CUNHA, 1991).

12

Em um plano analítico mais amplo, as consequências da reforma universitária de 1968, com especia destaque para a abertura para o ensino superior privado no Brasil, podem ser aprofundadas no texto de Carlos Benedito Martins (2009) anterior, que a pósgraduação compensou os efeitos da fragmentação acarretada pela reforma universitária, posto que permitiu a manutenção de um amplo diálogo da Pedadogia com outras áreas do conhecimento a partir da incorporação de professores. volvimento dessa área no contexto brasileiro. $\operatorname{Bittar}(2009$, p. 9) denomina a criação desses programas de "divisor de águas na história da pesquisa em educação brasileira”, uma vez que esses cursos acabaram por levar a pesquisa educacional, que era desenvolvida sobretudo nas instituições que apresentamos anteriormente, para o interior das universidades. De modo geral, pode-se afirmar que esse novo movimento de institucionalização pelo qual a investigação educacional passou estimulou um abandono do "pedagogismo" em que se encontrava, ${ }^{11}$ bem como a criação de uma bibliografia de referência (sendo alguns dos autores Luiz Antonio Cunha, Carlos Jamil Cury, Ester Buffa, Paolo Nosella e Dermeval Saviani), oriunda especialmente das primeiras dissertações e teses produzidas nos programas, e ainda trouxe para a pesquisa vieses teóricos como idealismo, economicismo, reprodutivismo, entre outros (BITTAR, 2009).

Além disso, a reforma universitária de 1968 foi decisiva para os rumos da pesquisa educacional. ${ }^{12}$ A extinção das cátedras e, com isso, a possibilidade de uma carreira acadêmica em moldes distintos, tal como o esfacelamento das faculdades de Filosofia, Ciências e Letras e a consequente criação das faculdades de Educação, são elementos determinantes para o início de um processo de autonomia da área da pesquisa educacional (CELESTE FILHO, 2004). Cunha (1992) apontou a criação dessas faculdades como verdadeira segregação institucional e alguns sociólogos, ${ }^{13}$ por exemplo, viam ainda, na criação das faculdades de Educação, uma perda do interesse científico pelo tema (COSTA; SILVA, 2003). É, pois, nesse contexto que as tensões entre os pesquisadores da área da Educação e os pesquisadores de outras áreas, em especial aquelas que compunham as antigas faculdades de Filosofia, Ciências e Letras, acirram-se. 
Cunha (1978), ao complementar a periodização feita por Gouveia (1971), indica que "teve início no ano de 1971 a quarta fase no desenvolvimento da pesquisa educacional no Brasil, caracterizado pelo papel preponderante desempenhado pelos programas de pós-graduação" (CUNHA, 1978, p. 3). Para este autor, a implementação dos programas de pós-graduação em Educação e o consequente incremento do volume de pesquisas, e a diversificação metodológica e de conteúdo que passou a ser registrada desde então são traços que revelam a proeminência da pós-graduação, que, por sua vez, contribuiu para o esvaziamento dos antigos órgãos de pesquisa educacional. Bittar (2009) afasta-se dessa organização proposta por Cunha (1978) e aponta para a existência de uma quarta fase somente depois do processo de redemocratização, em 1985, que vai até 2005, com a comemoração de 40 anos de existência da pós-graduação em Educação no Brasil.

Os processos de criação, institucionalização e consolidação que abrangem a pesquisa em Educação envolvem dois aspectos essenciais no caso brasileiro, nomeadamente: primeiro, as investigações propriamente educacionais eram desenvolvidas primordialmente fora do contexto universitário até a criação dos programas de pós-graduação em Educação, fato que ocorria de maneira concomitante à realização de estudos que possuíam fenômenos educativos tanto como objeto de investigação quanto como uma categoria explicativa para outros objetos em áreas como a Filosofia, a História, a Sociologia, a Economia, etc.; segundo, a autonomização de um espaço específico da educação no interior da universidade brasileira revela necessariamente transformações importantes nessa estrutura acadêmica. Convém ratificar que as pesquisas que tomam a educação como objeto ou mesmo como categoria explicativa para outros fenômenos continuam a ser desenvolvidas em áreas muito diversas mesmo depois da autonomização do espaço acadêmico da Educação para a qual estamos chamando atenção aqui.

As transformações na estrutura acadêmica em questão podem ser expressas, entre outros, pelos seguintes fatores: criação de faculdades de Educação; fomento destinado ao desenvolvimento de pesquisas nessa área; constituição de um grupo de professores, pesquisadores e obras de referência; a possibilidade de reprodução da própria área da Educação, com especial papel da pós-graduação, e a capacidade de formar os próprios quadros futuros; e o diálogo com as áreas que antes compunham as faculdades de Filosofia, Ciências e Letras (onde os cursos de formação de professores e o curso de Pedagogia estavam ancorados anteriormente), uma vez que parte dos professores dessas antigas faculdades foi compor as recém-criadas faculdades de Educação. Tais fatores permitiram, de um lado, uma autonomia relativa para a Educação na estrutura universitária em questão e, de outro, a sua gradativa inserção no “jogo universitário" (BOURDIEU; PASSERON, 2014). O grau de 
inserção e a consequente consolidação da área em questão, ao longo dos anos posteriores à institucionalização na universidade, podem ser observados por uma análise longitudinal das ações expressas, por exemplo, em: ampliação dos programas de mestrado e doutorado; fundação de associações regionais e nacionais de pesquisa em Educação; surgimento, consolidação e diversificação de eventos científicos nessa área, seja em nível local, nacional ou internacional; criação e fortalecimento de periódicos científicos em educação.

Das pesquisas isoladas e residuais dos Cursos Normais, passando pela socialização de conhecimentos para a prática docente e pela luta em torno da escola pública, com a ABE, bem como pelos esforços de nomes como Anísio Teixeira em Brasília e Lourenço Filho em São Paulo, à institucionalização da pesquisa educacional no Ministério da Educação por meio do Inep, do CBPE e dos CRPEs e, posteriormente, na instituição universitária, a trajetória dessa área no contexto brasileiro demonstra as condições sociais que possibilitaram a existência de um espaço acadêmico específico em Educação na estrutura universitária brasileira. ${ }^{14}$

Há que se entender esse espaço acadêmico específico da Educação de maneira relacional: ele mantém relação com o habitus mais geral do universo acadêmico brasileiro ao passo que desenvolveu, ao longo de sua história, um habitus próprio subordinado ao primeiro e carregado de especificidades da área do conhecimento em questão. Se já entendemos que os processos de socialização das regras e lógicas de cada campo social estão baseados em experiências educacionais, evidente se torna que a reprodução do espaço acadêmico da Educação também depende dessas questões. O que nos interessa apontar, neste caso, é que a análise de um campo específico acaba por revelar questões acerca da constituição de disposições também específicas em função das lógicas de funcionamento desse campo - esse constructo revela que as disposições dos doutorandos brasileiros em Educação somente podem ser analisadas à luz da própria trajetória dessa área.

\section{A REPRODUÇÃO DO CAMPO ACADÊMICO DA EDUCAÇÃO NO BRASIL: OS DOUTORANDOS E SUAS ASPIRAÇÕES}

[...] o "aspirante" à consagração científica tem de necessariamente incorporar as ideias, os conceitos, os métodos e as teorias já produzidas e sistematizadas numa construção nova, que tenta superar as anteriores. É assim que fins particulares de reconhecimento e legitimidade dos produtores individuais acabam se transformando, por uma lógica própria do funcionamento do campo, em algo proveitoso para o progresso da ciência, ou seja, a ampliação do conjunto de conhecimentos científicos. (GARCIA, 1996, p. 70) 
O campo científico é um espaço social caracterizado pelos nomes próprios, pelo indivíduo construído (BOURDIEU, 1984). Por isso, deve ser entendido também como um campo de forças, no qual as diferentes espécies de capital, bem como as disposições acadêmicas em jogo legitimam as posições desiguais que os pesquisadores ocupam. A relação, pois, entre agente e estrutura, neste caso, permite-nos afirmar que “O homo academicus é gerado no campo universitário ao mesmo tempo em que o estrutura, em um dado momento de sua história” (HEY, 2008, p. 101). Olhar, pois, para os aspirantes significa necessariamente olhar para o campo no qual eles aspiram a uma posição.

Deteremo-nos, a partir de agora, na caracterização dos doutorandos da área da Educação no Brasil a fim de demonstrar como suas aspirações estão incritas no habitus do espaço acadêmico específico da Educação. Os dados com os quais doravante trabalharemos foram retirados do banco de dados da pesquisa doutoral "(Ciências da) Educação no Brasil: autonomização dos espaços acadêmicos específicos": trata-se das respostas de 455 doutorandos regularmente matriculados em programas de pós-graduação em Educação - PPGE - a um questionário on-line que foi disponibilizado para tais estudantes por meio do contato e solicitação junto a todos os PPGEs brasileiros. ${ }^{15}$ Esse número representa aproximadamente $8,5 \%$ do universo de estudantes matriculados nos doutorados em Educação no Brasil no ano de 2015, posto que a Coordenação de Aperfeiçoamento de Pessoal de Nível Superior - Capes (2016) registrou 5.355 matrículas nesse período.

Os nossos respondentes compõem um grupo de 131 homens (28,8\% do total) e 324 mulheres $(71,2 \%)$, que apresentam uma variação etária significativa, a qual vai desde 24 até 62 anos, com uma concentração mais acentuada no intervalo entre 30 e 45 anos. A acentuada presença feminina nos cursos de doutorado em Educação ilustra um dos fatos recentes decorrentes das últimas décadas de escolarização no Brasil: a entrada cada vez mais proeminente das mulheres no ensino superior, seja nos cursos de graduação, seja nos cursos de pós-graduação. Guedes (2008), ao analisar os últimos quatro censos do Instituto Brasileiro de Geografia e Estatística - IBGE -, mostrou que, nos últimos trinta anos, as mulheres conseguiram reverter o quadro de desigualdade histórica e consolidar uma nova realidade em que são a maioria (60\%) dos formados entre os mais jovens e já possuem expressiva entrada em cursos tradicionalmente masculinos. No entanto, Ribeiro (2011) questiona tais avanços no que diz respeito à presença feminina nos institutos públicos de pesquisa vinculados ao Ministério da Ciência e Tecnologia: nestes espaços, a autora encontrou uma divisão sexual do trabalho na qual somente 32\% dos cargos de pesquisadores e tecnologistas é ocupado por mulheres e, dentre estas, somente $9 \%$ ocupam funções de gestão desses institutos. Essas questões são reveladoras de como as relações de gênero

\section{5}

Os dados acerca dos PPGE brasileiros foram recolhidos na página eletrônica da Capes - <http://www.capes. gov.br/>. Depois recorreu-se à busca dos contatos institucionais das secretarias desses programas nos próprios sites dos PPGE. 
se colocam como um elemento significativo de debate no interior do campo acadêmico brasileiro mais amplo.

Nesse contexto, o professor Dilvo Ristoff (2006) chegou à conclusão de que os cursos mais procurados pelos homens são ligados à engenharia, tecnologia, indústria e computação, enquanto os mais procurados pelas mulheres são relativos a serviços e educação para a saúde e para a sociedade (secretariado, psicologia, nutrição, enfermagem, serviço social, pedagogia) e, ainda segundo esse autor, essa é uma tendência que se mantém nos mestrados, nos doutorados e até mesmo na própria docência no ensino superior. O espaço acadêmico específico da Educação tem se constituído historicamente, portanto, com forte dominância da participação das mulheres - provavelmente um aprofundamento no sentido de mapear as posições que as mulheres ocupam em relação às posições masculinas dentro desse espaço específico possibilitaria um esquadrinhamento da questão. ${ }^{16}$

Acerca da trajetória formativa dos nossos respondentes, buscamos mapear os cursos, instituições e áreas de interesse e, com tais informações, é possível analisar, de um lado, os diálogos que a área da Educação estabelece com outras áreas do conhecimento por meio dessas trajetórias e, de outro, como o quadro de possibilidades de investi-

Exercício que ultrapassa os nossos objetivos para este artigo; porém, ganha

relevância no quadro de horizontes de possibilidades futuras de estudos. mentos dos doutorandos na área aqui analisada é revelador das relações de poder que emergem dos trânsitos de agentes interáreas no campo acadêmico. Comecemos, então, a observar tais questões por meio do Gráfico 1:

\section{GRÁFICO 1}

CURSOS DE GRADUAÇÃO FREQUENTADOS PELOS DOUTORANDOS EM EDUCAÇÃO NO BRASIL

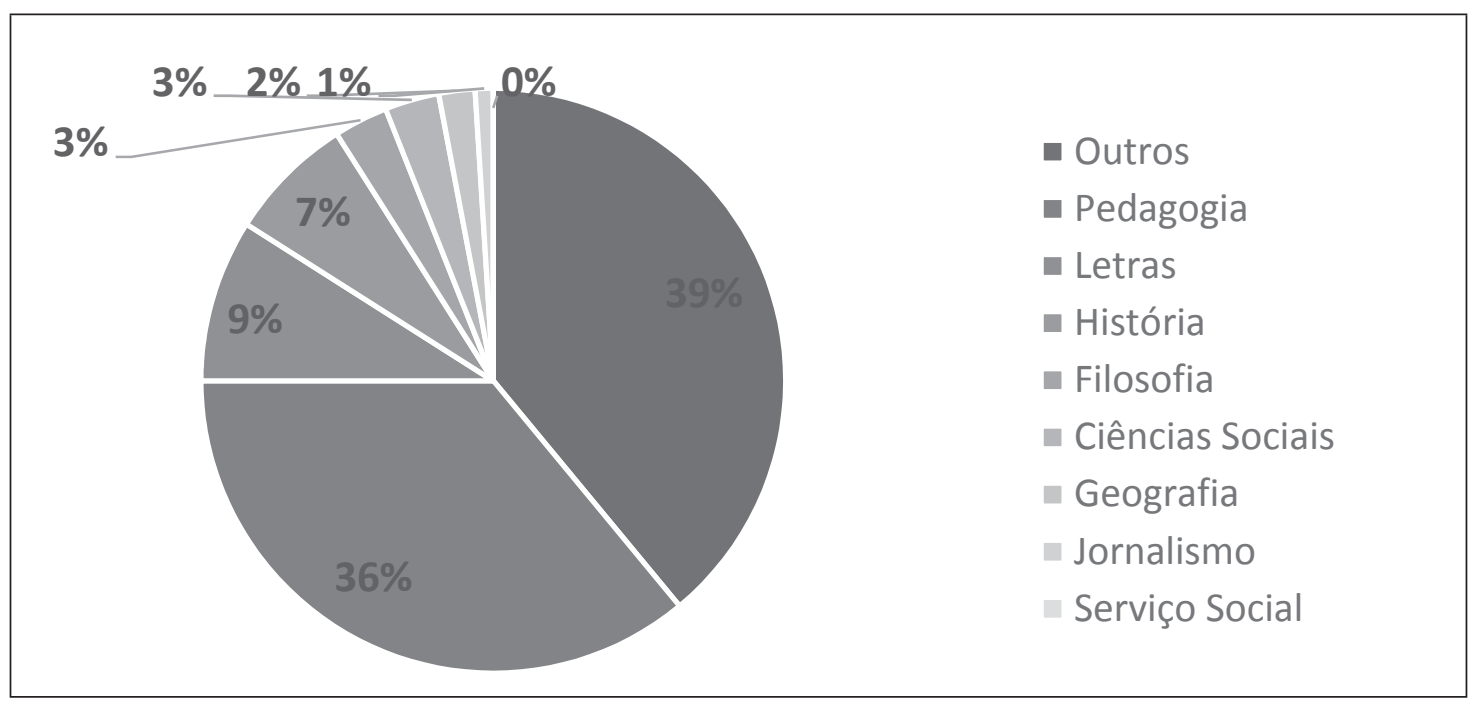

Fonte: Elaboração das autoras (2017).

Uma diversidade de áreas é encontrada no início da trajetória acadêmica dos nossos respondentes: Pedagogia aparece como curso 
mais frequentado (por 165 doutorandos ou 36,3\% do total de respondentes), seguido de Letras (40 doutorandos ou 8,8\%), História (com 33 doutorandos perfazendo 7,3\%), Filosofia (13 doutorandos ou 2,9\%), Ciências Sociais (12 respondentes ou 2,6\%), Geografia (com 7 doutorandos ou 1,5\%), Jornalismo (5 respondentes ou 1,1\%) e Serviço Social (2 respondentes ou $0,4 \%$ ). A categoria "Outros" acaba por ratificar essa diversidade, uma vez que concentra 39,1\% dos respondentes, o que equivale, em números absolutos, a 178 doutorandos, e abarca cursos de todas as áreas do conhecimento.

Antes de aprofundarmos o debate acerca dessa questão da confluência de cursos bastante diversos encontrarem-se representados pelos doutorandos em PPGEs, vejamos como as trajetórias formativas desenvolveram-se após a graduação: a) ao tomarmos os anos de conclusão da graduação à análise, deparamos-nos com uma heterogeneidade que vai desde 1972 até 2014, o que demonstra uma gama de percursos destoantes uns dos outros, mas que acabam por "se encontrar" no doutorado em Educação na altura da aplicação do nosso instrumento (maio a junho de 2016); b) apenas 23,5\% (107 estudantes) dos respondentes possui uma segunda graduação, contra 76,5 \% (348 estudantes), sendo a Pedagogia o curso de maior expressão apontado nesse quesito, com $34,9 \%$, e coexistindo, mais uma vez, com cursos de todas as áreas do conhecimento; c) já no que se refere à pós-graduação lato sensu, temos que 64\% dos doutorandos que participaram da pesquisa (ou 291 estudantes) possuem alguma pós-graduação desse tipo, enquanto 36\% (164 em números absolutos) não possuem. Dos que têm alguma especialização desse gênero, 251 (ou 86\%) a fizeram na área da Educação (com destaques para a Gestão e a Psicopedagogia) e 40 a fizeram em outras áreas (com destaque para Letras, História, Administração e Saúde Pública).

No contexto dessa discussão acerca da diversidade que marca as trajetórias dos nossos respondentes, observemos, por meio do Gráfico 2, as áreas nas quais os doutorandos realizaram seus mestrados: 


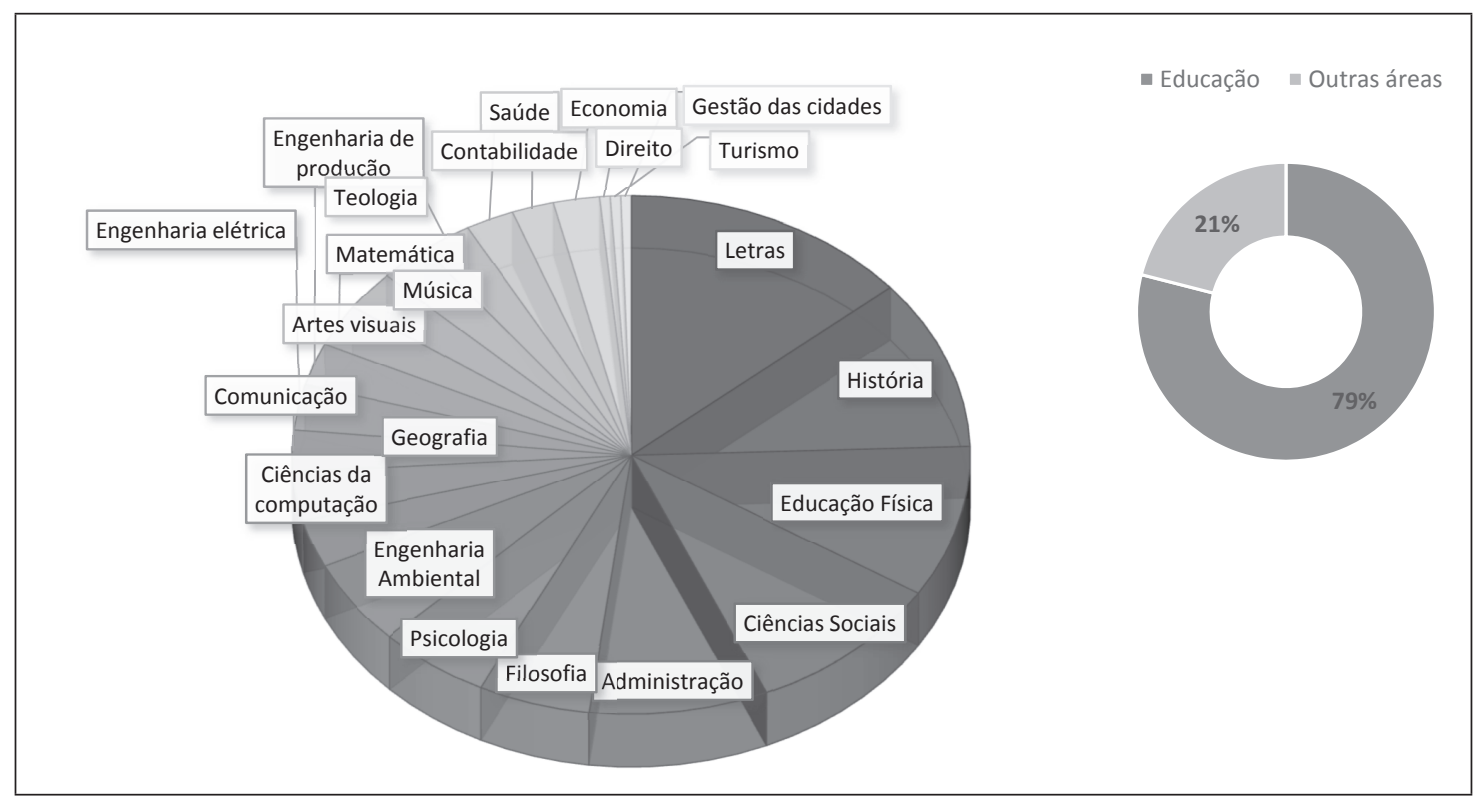

Fonte: Elaboração das autoras (2017).

As trajetórias acadêmicas dos doutorandos apresentam maior encaminhamento para o espaço específico da Educação no momento da realização de seus mestrados. O Gráfico 2 sinaliza uma busca pelo grau de mestre nessa área por parte de 361 respondentes (79\%), ao passo que 94 respondentes (21\%) obtiveram esse grau em áreas distintas, dentre as quais destacam-se: Letras (13,8\% dos 94 estudantes que concluíram mestrados em outras áreas), História (10,6\%), Educação Física (9,5\%), Ciências Sociais $(9,5 \%)$, Administração (8,5\%), Filosofia (5,3\%), Psicologia $(5,3 \%)$ e Engenharia Ambiental (5,3\%). As demais áreas, mesmo com pouca expressividade percentual, revelam a diversidade de domínios que acabam por dialogar com a Educação. São elas: Ciências da Computação, Geografia, Comunicação, Engenharia Elétrica, Engenharia de Produção, Matemática, Artes Visuais, Música, Teologia, Saúde, Contabilidade, Economia, Direito, Turismo e Gestão das Cidades. Destaca-se, nesse contexto, mais uma vez, a forma como os percursos aqui apresentados, mesmo já se conformando à área da pesquisa educacional em sua maioria, trazem a marca do diálogo entre áreas diversas como elemento de entrada na área da Educação no doutoramento, por exemplo. Pode-se relacionar esse diálogo, que se ratificará nas linhas de interesse às quais os nossos respondentes alinham-se no doutorado, com um debate clássico da própria área científica da Educação: sua composição com (e a partir de) outras disciplinas e áreas do conhecimento. Acerca desse debate, Mariana Gaio Alves e Nair Azevedo (2010, p. 1) nos esclarecem que: 
A investigação em Educação é um campo de acção e pensamento multi-referenciado se tomarmos em consideração a diversidade de perspectivas disciplinares, epistemológicas e metodológicas que integra, de formas múltiplas e frequentemente imbuídas de tensões e ambiguidades. É, igualmente, um campo de acção e pensamento multi-referenciado se recordarmos a diversidade de práticas educativas, bem como de percursos, contextos profissionais e áreas disciplinares de formação de base dos sujeitos que investigam em educação, a qual origina uma multiplicidade de trajectos e interesses de pesquisa no seio desta comunidade científica. Noutros termos, neste campo científico coexistem diversas perspectivas disciplinares e abordagens metodológicas, ao mesmo tempo que a comunidade científica é composta por profissionais de vários contextos de educação/formação e segmentos do sistema educativo. (2010, p. 1)

A multi-referencialidade apontada pelas autoras pode ser visualizada não apenas pelos percursos que mostramos até o momento, mas também pelas áreas de especialização que os respondentes acabaram por seguir no doutoramento em Educação. No âmbito das diferentes matrizes de pensamento que contribuíram para a cientifização e universitarização da Educação ao redor do mundo, a problemática da difícil tarefa de conciliação de tantas referencialidades oriundas de áreas completamente distintas no espaço da pesquisa em Educação emerge como um debate acirrado. A cientificidade da área educacional não é um tópico novo na discussão acerca da sua epistemologia, sendo possível afirmar que os processos de universitarização foram acompanhados de reflexões realizadas pelos próprios sujeitos que deles fizeram parte. Nesse sentido, questões como especulação, moralidade, método, ideologia, prática, teoria, aplicabilidade, qualidade rondaram os esforços de construção do estatuto científico da área da Educação (MADEIRA, 2009); passadas décadas da emergência do campo acadêmico em Educação no Brasil, por exemplo, tais questões ainda fazem parte do rol de críticas dirigidas a essa área. Compor o universo acadêmico como uma disciplina, ou seja, tornar-se um espaço acadêmico específico dentro das instituições de ensino superior não significou, para a Educação no Brasil, a garantia automática de prestígio frente às demais disciplinas que passaram a coexistir de forma igual do ponto de vista institucional, porém distintas do ponto de vista do poder simbólico que carregam.

Vamos agora enveredar pelos dados relativos ao doutorado dos sujeitos deste estudo, com o intuito de continuar aprofundando as relações entre os seus trajetos e o próprio desenvolvimento do campo da Educação no Brasil, bem como a materialidade desta multi-referencialidade do campo da Educação por meio de suas subáreas. Antes mesmo de 
Decidimos elencar aqui somente a distribuição espacial das instituições nas quais os estudantes realizam seus doutorados, pois seria demasiado extenso trazer a distribuição relativa a toda a trajetória acadêmica. Nesse sentido, vale a pena apontar que um trânsito entre distintas instituições marca essas trajetórias.

adentrarmos os dados específicos acerca das áreas de especialização dos doutorandos, vale a pena salientar duas questões de caracterização dos mesmos: a) no mestrado, uma tímida maioria dos estudantes recebeu bolsa para a realização de seus estudos (242 ou 53,2\%), já no doutorado, apenas 171 estudantes (ou 37,6\%) receberam algum tipo de financiamento; b) $89,5 \%$ dos respondentes exerceram algum tipo de trabalho durante a sua formação acadêmica, sendo que, durante o mestrado, o número é de mais de 73\%, e, durante o doutorado, mais de $70 \%$ dos respondentes trabalharam.

Quanto à distribuição espacial das instituições nas quais nossos respondentes realizam seus doutorados em Educação, temos o seguinte cenário: Sudeste (48\% ou 220 estudantes), com destaque para a Universidade Estadual Paulista - Unesp (com 59 estudantes), USP (54 estudantes) e Universidade Federal de São Carlos - UFSCar (40 estudantes); Nordeste (24\% ou 109 estudantes), com destaque para Universidade Federal de Pernambuco - UFPE (51 estudantes) e Universidade Federal do Rio Grande do Norte - UFRN (31 estudantes); Sul (23\% ou 104 estudantes), com destaque para Universidade Federal de Santa Catarina - UFSC (29 estudantes) e Universidade Federal de Santa Maria - UFSM (19 estudantes); Centro-Oeste (3\% ou 14 estudantes), com destaque para Pontifícia Universidade Católica de Goiás - PUC-GO (7 estudantes); Norte ( $2 \%$ ou 8 estudantes), com a presença somente da Universidade Federal do Pará - UFPA. ${ }^{17}$

Ao serem questionados acerca da área ou linha de especialização em que estão trabalhando no doutorado, os nossos respondentes acabam por configurar o quadro abaixo:

\section{GRÁFICO 3}

ÁREAS DE ESPECIALIDADE DOS RESPONDENTES NOS DOUTORADOS EM EDUCAÇÃO NO BRASIL

- Outras

- Educação

- História da Educação

- Formação de professores

- Política educacional

- Sociologia da Educação

- Filosofia da Educação

- Educação e Comunicação

- TICs e EAD

- Educação especial

- Currículo

- Psicologia

- Interculturalidade

- Linguagem

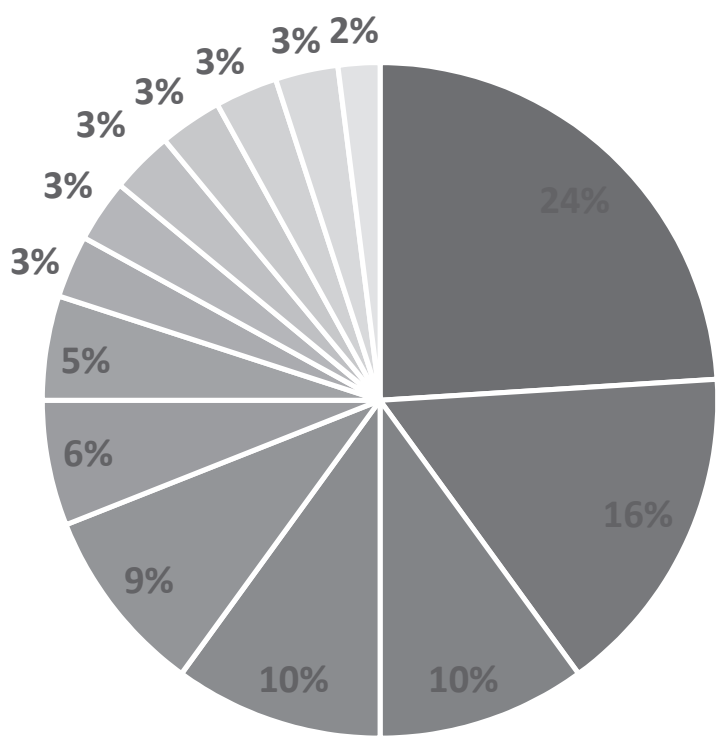

Fonte: Elaboração das autoras (2017). 
Ao tratarmos dessa miscelânea de linhas ou áreas de especialização apontadas pelos estudantes, estamos concomitantemente tratando da diversidade de subáreas e temas que fazem parte do espaço acadêmico específico da Educação no cenário brasileiro. Nesse sentido, o Gráfico 3 nos apresenta a distribuição dessas áreas e nos possibilita observar que muitos doutorandos responderam "Educação" como área de especialização (75 mais precisamente, o que equivale a 16\%); na sequência, vale a pena atentar para a forte presença das áreas da História da Educação (46 sujeitos ou 10\%), Formação de Professores (com 9,8\% ou 45 sujeitos), Política da Educação (9,4\% ou 43 respondentes), Sociologia da Educação (6\% ou 28 sujeitos), Filosofia da Educação (22 sujeitos ou 5\%), etc. E ainda se destaca a categoria denominada "Outras”, uma vez que condensa áreas não muito expressivas do ponto de vista percentual, mas que corroboram a tese da diversidade de disciplinas com as quais a Educação tem historicamente dialogado e ainda abrem a discussão acerca da consolidação da área da Educação face à especialização crescente das suas linhas de investigação - destacamos, dentro dessa categoria, as seguintes linhas: Ensino e Aprendizagem, Educação Ambiental, Educação Infantil, Gestão educacional, Trabalho e Educação, Cotidiano escolar, Representação Social, Ensino Superior, Educação e Espiritualidade.

A partir das reflexões de Canário (2005) acerca da área das Ciências da Educação - ele refere-se aqui ao contexto português e por isso o termo destoa do adotado no Brasil -, é possível compreender o espaço científico da pesquisa em Educação como o resultado da referência a um conjunto de saberes e de práticas profissionais, de um lado, e da contribuição de disciplinas científicas já anteriormente estabelecidas (tais como a Sociologia, a Psicologia, a Economia, a Filosofia, etc.), de outro. O que gerou, nos diferentes países, ênfases, abordagens, escolas e tradições completamente diversas e complexas na sua estruturação e na própria legitimidade frente às áreas já estabelecidas e até prestigiosas. Outros autores já realizaram o exercício de tipificação do desenvolvimento dessa área (BERGER, 1992; BALL; FORZANI, 2007; FURLONG; LAWN, 2009) e, no caso brasileiro, faz-se mister reconhecer esse duplo movimento de diálogo com disciplinas outras e de especialização da própria área educacional, pois, desse modo, conseguimos captar o porquê da coexistência de linhas de pesquisa, temas, objetos, métodos e abordagens que advêm dessas duas frentes. Perspectivar o campo da pesquisa em Educação no Brasil dessa maneira nos auxilia a superar um olhar moralizante sobre as características desenvolvidas ao longo de sua história: essa diversidade é uma característica que foi construída sócio-historicamente e deve ser objetivada como tal.

O habitus do próprio campo da Educação, que historicamente está atrelado ao diálogo com diferentes áreas do conhecimento, expressa-se no caso dos doutorandos que responderam ao nosso questionário. 
Ainda nessa discussão sobre a relação entre as disposições, as trajetórias dos estudantes e as lógicas próprias do espaço da Educação, as aspirações que esses estudantes possuem constituem um elemento significativo de como as suas experiências até esse momento formativo do doutorado inscreveram-se em seus corpos e auxiliaram a moldar suas expectativas de vida, sobretudo suas expectativas profissionais. De outro lado, essas mesmas aspirações e expectativas encontram-se associadas ao desenvolvimento da Educação enquanto espaço acadêmico específico dentro da estrutura universitária brasileira. Como esse processo tem duplo papel - na esfera individual e na esfera coletiva -, busca-se aqui compreender essa faceta da expectação como um elemento que se ajusta de acordo com o campo, ao passo que interpela e modifica o próprio campo.

A pergunta que fizemos aos doutorandos foi: "O que você busca com o doutorado na área da Educação?”. A partir das respostas, foi possível construir o Gráfico 4:

\section{GRÁFICO 4}

ASPIRAÇÕES DOS DOUTORANDOS EM EDUCAÇÃO NO BRASIL ${ }^{18}$

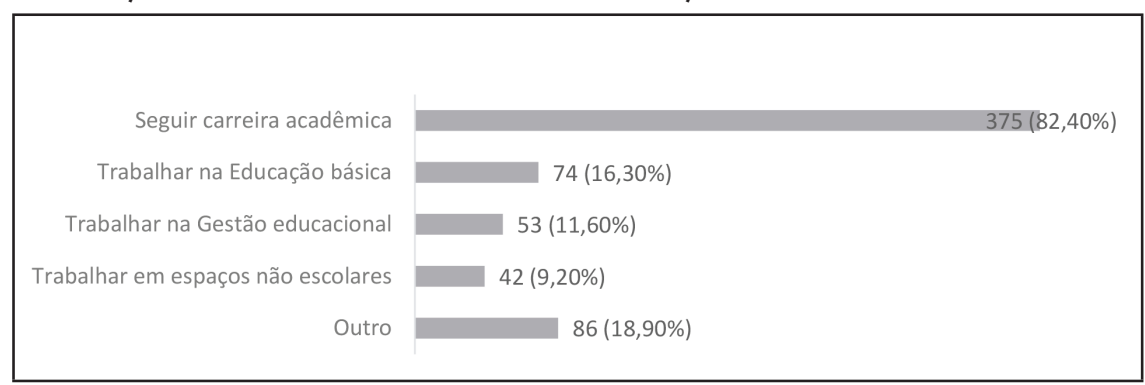

Fonte: Elaboração das autoras (2017).

Sabendo, então, que as disposições são geradas na confluência da estrutura do espaço social e das propriedades ali atuantes, é possível inferir que as disposições acadêmicas dos doutorandos, de modo geral, foram (e são) geradas nos espaços dos quais eles participam ao longo do processo de formação intelectual. Além disso, há que se apontar como elementos importantes para se compreender tal processo formativo: as disposições adquiridas no ambiente familiar, na trajetória escolar e acadêmica e nas demais experiências de socialização vividas ao longo da vida. As trajetórias - da infância à vida universitária - ganham interrogações vinculadas à tentativa de compreender o que cerca o processo de construção de agentes dispostos a “jogar o jogo” do campo científico. gráfico ultrapassam o nosso universo de respondentes (455 sujeitos) porque eles puderam apontar mais de uma alternativa à questão.
Essa discussão acerca da disposição para entrar e pleitear uma posição no mundo acadêmico ganha sentido quando observamos, com auxílio do Gráfico 4, que mais de $82 \%$ dos doutorandos que participaram do estudo desejam seguir a carreira acadêmica. 
Tal desejo não pode ser compreendido em si mesmo - bem como as demais ambições que o Gráfico 4 aponta. Todas as aspirações que os estudantes apresentaram possuem uma complexa rede de experiências que lhes confere significado:

\footnotetext{
Um cientista é o campo científico feito pessoa, cujas estruturas cognitivas são homólogas às estruturas do campo e, por essa razão, constantemente ajustadas às expectativas inscritas no campo. [...] Cada ato científico é, como qualquer prática, o produto do encontro de duas histórias, a história corporificada na forma de disposições e a história objetivada na própria estrutura do campo assim como em objetos técnicos (tais como instrumentos), publicações etc. (BOURDIEU, 2008, p. 35, grifos nossos)
}

Buscar um doutorado na área da Educação e aspirar ao prosseguimento da carreira acadêmica são tomadas de decisões realizadas pelos sujeitos que possuem significado no âmbito de suas trajetórias formativas e na própria trajetória do campo em questão. Ao "entrarem" para esse espaço acadêmico específico - seja por meio de um percurso linear ou de uma formação híbrida (com entrada em outras áreas antes do doutrado em Educação, ou mesmo com um espaço temporal grande entre um nível e outro, como mostramos anteriormente por meio dos dados) -, os estudantes acreditaram na credibilidade da área, apostaram suas "fichas" e investiram tempo, dinheiro e tudo o que foi necessário para constituir e consolidar os seus capitais ou as suas armas para o jogo acadêmico. A relação entre as disposições dos agentes, estruturas do campo e as expectativas, apontada por Bourdieu (2008), contribui para a nossa compreensão em torno do expressivo desejo dos nossos respondentes em seguirem carreira acadêmica. Isso porque é possível ligarmos essa aspiração dos doutorandos à própria consolidação da área da Educação como um espaço acadêmico específico no Brasil, passadas mais de quatro décadas da criação da pós-graduação nessa área (BITTAR, 2009). No mesmo contexto da consolidação da área da pesquisa educacional, temos uma distinção bastante significativa, dentre as áreas de possível atuação que a docência permite, a qual faz emergir um certo prestígio atribuído à carreira acadêmica - muitas vezes em detrimento de outros espaços de atuação docente, como os demais apontados no Gráfico 4.

Se o campo da Educação construiu seu habitus científico e acadêmico no Brasil a partir dos processos históricos de sua constituição, institucionalização e consolidação, como mostramos no segundo tópico deste artigo, é um movimento esperado que os aspirantes a uma posição nesse campo se apropriem das regras e lógicas desse espaço e também aspirem a uma posição dentro da estrutura desse espaço. Somente a partir dos processos que culminaram com a consolidação da investigação 
em Educação realizada nas instituições de ensino superior brasileiras foi possível não apenas constituir um habitus próprio e que age nas disposições dos agentes e dos aspirantes, mas também, a partir dessas disposições e aspirações, possibilitar o processo de formação dos novos quadros que ocuparão as posições e sustentarão esse espaço. Os novos quadros acabam por desempenhar, mais tarde, as funções educacionais de socialização frente às lógicas do campo que possibilitarão uma renovação de quadros constante e uma reprodução do próprio campo. ${ }^{19}$

\section{CONSIDERAÇÕES FINAIS}

A reflexividade do próprio campo acadêmico não é uma atividade inédita e, provavelmente, a consolidação dos espaços de produção acadêmica no âmbito das universidades - e aqui reportamo-nos para além do caso brasileiro - é um fator decisivo para o exercício da autoanálise dos agentes que compõem o próprio campo científico que interrogam. Tomar como objeto de investigação o próprio campo acadêmico é, pois, um exercício intelectual que permite analisar o jogo que é estabelecido e mantido pelos próprios agentes que compõem o campo, bem como suas lógicas de funcionamento, seus capitais legítimos, os investimentos que os agentes realizam na entrada, permanência e na busca por um lugar dentro dessa estrutura simbólica. Tomamos à análise, neste artigo, o espaço acadêmico específico da Educação no Brasil como um caso exemplificativo do jogo acadêmico.

Demonstramos, primeiramente, como as relações educativas sustentam as possibilidades de reprodução de um campo social qualquer, uma vez que o "sentido do jogo" é partilhado e socializado por meio de processos de ensino e aprendizagem, incluindo não formais ou curriculares. E que são essas relações educativas as responsáveis pela apreensão, por meio dos entrantes, do habitus próprio de determinado espaço social. Com a área da pesquisa educacional não é diferente, e, nesse sentido, destacamos ainda as condições sociais de possibilidade de universitarização dessa área no contexto brasileiro como elementos influenciadores da construção do habitus específico da Educação. Uma perspectiva dialética, neste caso, nos auxiliou a compreender que os processos sociais mais amplos, conjugados com os processos internos de definição de um campo, acabam por influenciar os rumos que o próprio campo toma e ainda a constituição de um habitus próprio.

Por fim, conjugamos esses dois exercícios com uma frente analítica que acabou por demonstrar como as trajetórias e as aspirações dos social em si, mas não indica que mudanças e revoluções internas não possam ocorrer doutorandos em Educação, ou seja, os aspirantes a uma posição nesse campo, foram forjadas no âmbito do próprio habitus do campo, ao passo que o modificam e permitem-nos falar em continuidade e reprodução do campo por meio da formação de novos quadros que se retroalimentam 
pelos processos educativos que sustentam o campo da Educação e todos os demais campos sociais.

Por um lado, temos um conjunto de doutorandos com as características que buscamos debater neste artigo, que são em síntese: robusta presença feminina; maior concentração no Sudeste do Brasil; perfil etário diversificado, com concentração entre os 30 e 45 anos; diversidade nos cursos de graduação e acentuada realização de cursos de pós-graduação, estes últimos já com significativa relação com a área educacional; realização de mestrado já predominantemente na área da Educação; distribuição pelas mais variadas linhas de especialização que compõem os doutoramentos da área no contexto brasileiro; e com aspirações marcadamente acadêmicas. Mas, por outro lado, essa caracterização não comunica somente sobre os estudantes; ela exprime as condições do próprio campo acadêmico da Educação no Brasil.

\section{REFERÊNCIAS}

ALVARENGA, Lídia. A institucionalização da pesquisa educacional no Brasil: um estudo bibliométrico dos artigos publicados na Revista Brasileira de Estudos Pedagógicos 1944-74. 1996. 261. Tese (Doutorado em Educação) - Universidade Federal de Minas Gerais, Belo Horizonte, 1996.

ALVES, Mariana Gaio; AZEVEDO, Nadir Rios (Ed.). Investigar em educação: desafios da construção de conhecimento e da formação de investigadores num campo multi-referenciado. Caparica: UIED/FCT, Universidade Nova de Lisboa, 2010.

APPLE, Michael. Repensando ideologia e currículo. In: MOREIRA, Antonio Flavio; SILVA, Tomaz Tadeu (Org.). Currículo, cultura e sociedade. São Paulo: Cortez, 1994. p. 39-58.

BALL, Deborah Loewenberg; FORZANI, Francesca M. What makes education research “educational”? Educational Researcher, v. 36, n. 9, p. 529- 540, 2007.

BERGER, Guy. A investigação em educação: modelos sócio-epistemológicos e inserção institucional. Revista de Psicologia e de Ciências da Educação, n. 314, p. 23-26, 1992.

BITTAR, Marisa. A pesquisa em educação no Brasil e a constituição do campo científico. Revista HISTEDBR On-line, Campinas, n. 33, p. 3-22, mar. 2009.

BLOCH, Marc. Apologia da história, ou o ofício do historiador. Rio de Janeiro: Jorge Zahar, 2001.

BOURDIEU, Pierre. Outline of a theory of practice. 18. ed. Cambridge: Cambridge University Press, 1977.

BOURDIEU, Pierre. O campo científico. In: ORTIZ, Renato (Org.). Pierre Bourdieu. São Paulo: Ática, 1983. p. 122-155. (Coleção Grandes cientistas sociais).

BOURDIEU, Pierre. Homo academicus. Paris: Minuit, 1984.

BOURDIEU, Pierre. Coisas ditas. Tradução de Cássia Silveira e Denise Pegorin. São Paulo: Brasiliense, 1990.

BOURDIEU, Pierre. Razões práticas: sobre a teoria da ação. 9. ed. Tradução de Marisa Corrêa. Campinas: Papirus, 1996.

BOURDIEU, Pierre. Meditações pascalianas. Rio de Janeiro: Bertrand Brasil, 2001.

BOURDIEU, Pierre. Para uma sociologia da ciência. Tradução de Pedro Elói Duarte. Lisboa, PT: Edições 70, 2008.

BOURDIEU, Pierre. 0 poder simbólico. Tradução de Fernando Tomaz. 15. ed. Rio de Janeiro: Bertrand Brasil, 2011. 
BOURDIEU, Pierre; CHAMBOREDON, Jean-Claude; PASSERON, Jean-Claude. El oficio del sociólogo: pressupuestos epistemológicos. Buenos Aires: Siglo XXI, 2002.

BOURDIEU, Pierre; EAGLETON, Terry. A doxa e a vida cotidiana: uma entrevista. In: ZIZEK, Slavoj (Org.). Um mapa da ideologia. Tradução de Vera Ribeiro. Rio de Janeiro: Contraponto, 1996. p. 265-278.

BOURDIEU, Pierre; PASSERON, Jean-Claude. Os herdeiros: os estudantes e a cultura. Tradução de Ione Ribeiro Valle e Nilton Valle. Florianópolis: Editora da UFSC, 2014.

CAMPOS, Maria. Malta; FÁVERO, Osmar. A pesquisa em educação no Brasil. Cadernos de Pesquisa, São Paulo, n. 88, p. 5-17, fev. 1994.

CANÁRIO, Rui. O que é a escola? Um olhar sociológico. Porto: Porto, 2005.

CARVALHO, Marília Pinto de. O conceito de gênero: uma leitura com base nos trabalhos do GT Sociologia da Educação da ANPEd (1999-2009). Revista Brasileira de Educação, v. 16, n. 46, p. 99-117, jan./abr. 2011.

CATANI, Afrânio Mendes. Origem e destino: pensando a sociologia reflexiva de Bourdieu. Campinas, SP: Mercado de Letras, 2013.

CELESTE FILHO, Macioniro. A reforma universitária e a criação das faculdades de educação. Revista Brasileira de História da Educação, n. 7, p. 161-188, jan./jun. 2004.

COORDENAÇÃO DE APERFEIÇOAMENTO DE PESSOAL DE NÍVEL SUPERIOR. Distribuição de discentes de pós-graduação no Brasil por área de avaliação (ao final do ano). Brasília: GEOCAPES, 2016. Disponível em: <http://geocapes.capes.gov.br/geocapes2/>. Acesso em: maio 2017

COSTA, Márcio; SILVA, Graziella. M. D. Amor e desprezo: o velho caso entre sociologia e educação no âmbito do GT-14. Revista Brasileira de Educação, n. 22, p. 101-120, jan./abr. 2003.

CUNHA, Luiz Antônio. Os (des)caminhos da pesquisa na pós-graduação em educação. Curitiba, UFPR, 1978.

CUNHA, Luiz Antônio. Pós-graduação em educação: no ponto de inflexão? Cadernos de Pesquisa, São Paulo, n. 77, p. 63-67, maio 1991.

CUNHA, Luiz Antônio. Reflexões sobre as condições sociais de produção da sociologia da educação: primeiras aproximações. Tempo Social: Revista de Sociologia da USP, v. 4, n. 1-2, p. $169-182,1992$.

CURY, Carlos Roberto Jamil. Trinta por trinta: dimensões da pós-graduação em educação. Revista Brasileira de Educação, v. 13, n. 37, p. 162-167, jan./abr. 2008.

DURKHEIM, Émile. As regras do método sociológico. Tradução de Paulo Neves. 2. ed. São Paulo: Martins Fontes, 1999. (Coleção Tópicos).

FÁVERO, Maria de Lourdes de Albuquerque. A UDF, sua vocação política e científica: um legado para se pensar a universidade hoje. Pro-Posições, Campinas, v. 15, n. 3, p. 143-162, set./dez. 2004.

FÁVERO, Maria de Lourdes de Albuquerque. Anísio Teixeira e a Universidade do Distrito Federal. Revista Brasileira de História da Educação, n. 17, p. 161-180, maio/ago. 2008.

FERREIRA, Luiz Otávio; BRITTO, Nara. Os intelectuais no mundo e o mundo dos intelectuais: uma leitura comparada de Pierre Bourdieu e Karl Mannheim. In: PORTOCARRERO, V. (Org.). Filosofia, história e sociologia das ciências I: abordagens contemporâneas. Rio de Janeiro: Fiocruz, 1994. p. 133-150. Disponível em: <http://books.scielo.org/id/rnn6q/pdf/ portocarrero-9788575414095.pdf>. Acesso em: maio 2017.

FERREIRA, Márcia Santos. Os centros de pesquisas educacionais do INEP e os estudos em ciências sociais sobre a educação no Brasil. Revista Brasileira de Educação, v. 13, n. 38, p. 279-292, maio/ago. 2008.

FIORENTINI, Dario et al. Formação de professores que ensinam matemática: um balanço de 25 anos da pesquisa brasileira. Educação em Revista, Belo Horizonte, n. 36, p. 137-60, 2002. Dossiê: educação matemática. 
FRIGOTTO, Gaudêncio. Os circuitos da história e o balanço da educação no Brasil na primeira década do século XXI. Revista Brasileira de Educação, v. 16, n. 46, p. 235-254, jan./abr. 2011. Conferência de Abertura da $33^{\text {a }}$ Reunião Anual da ANPEd.

FURLONG, John; LAWN, Martin. The disciplines of education in the UK: between the ghost and the shadow. Oxford Review of Education, London, v. 35, n. 5, p. 541-552, 2009.

GARCIA, Maria Manuela Alves. O campo das produções simbólicas e o campo científico em Bourdieu. Cadernos de Pesquisa, São Paulo, n. 97, p. 64-72, 1996.

GATTI, Bernardete Angelina. Pós-graduação e pesquisa em educação no Brasil: 1978-1981. Cadernos de Pesquisa, São Paulo, n. 44, p. 3-17, 1983.

GATTI, Bernardete Angelina. A construção da pesquisa em educação no Brasil. Brasília: Plano, 2002. (Pesquisa em Educação).

GOERGEN, Pedro. A pesquisa educacional no Brasil: dificuldades, avanços e perspectivas. Em Aberto, Brasília, ano 5, n. 31, p. 1-17, jul./set. 1986.

GOUVEIA, Aparecida Joly. A pesquisa educacional no Brasil. Cadernos de Pesquisa, São Paulo, n. 1, p. 1-47, jul. 1971.

GUEDES, Moema de Castro. A presença feminina nos cursos universitários e nas pós-graduações: desconstruindo a idéia da universidade como espaço masculino. História, Ciências, Saúde: Manguinhos, Rio de Janeiro, v. 15, p.117-132, jun. 2008. Suplemento.

HEY, Ana Paula. Esboço de uma sociologia do campo acadêmico: a educação superior no Brasil. São Carlos: EdUFSCar, 2008.

IANNI, Octavio. O colapso do populismo do Brasil. 2. ed. Rio de Janeiro: Civilização Brasileira, 1971.

KANT, Immanuel. Sobre a Pedagogia. 2. ed. Piracicaba: Unimep,1999.

LEÃO, Carneiro. Apóstolo e realizador. In: Anísio Teixeira: pensamento e ação. Rio de Janeiro: Civilização Brasileira, 1960. p. 93-105.

MADEIRA, Ana Isabel. O ensino superior da Europa e a sua relação com a América Latina: a cooperação entre Portugal e Brasil. Revista Brasileira de Política e Administração da Educação, v. 25, n. 1, p. 33-60, jan./abr. 2009.

MANGI, Luís Claudio Miranda. Durável e/ou modificável? Reflexões acerca da noção de habitus em Pierre Bourdieu. In: Encontro da ANPAD, 36, 2012, Rio de Janeiro. Anais... Rio de Janeiro: ANPAD, 2012. p. 1-15. Disponível em: <http://www.anpad.org.br/admin/pdf/2012_EOR1020.pdf>. Acesso em: maio 2017.

MARTINS, Carlos Benedito. A reforma universitária de 1968 e a abertura para o ensino superior privado no Brasil. Educação e Sociedade, Campinas, v. 30, n. 106, p. 15-35, jan./abr. 2009.

MELLO, Guiomar Namo de. Pesquisa educacional do Brasil. Cadernos de Pesquisa, São Paulo, n. 46, p. $67-82,1983$.

MEUCCI, Arthur. O papel do habitus na teoria do conhecimento: entre Aristóteles, Descartes, Hume, Kant e Bourdieu. 2009. Dissertação (Mestrado) - Universidade de São Paulo, São Paulo, 2009.

MOTTA, Rodrigo Patto Sá. As universidades e o regime militar: cultura política brasileira e modernização autoritária. Rio de Janeiro: Zahar, 2014.

PERRENOUD, Philippe. La construcción del êxito y del fracaso escolar. Madrid: Morata, 1996.

PERRENOUD, Philippe et al. (Org.). Formando professores profissionais: quais estratégias? Quais competências? Porto Alegre: Artmed, 2001.

RIBEIRO, Ludmila Maria Batista de Brito. Gênero e ciência: a presença feminina em institutos públicos de pesquisa. In: Encontro da ANPAD, 35, 2011, Rio de Janeiro. Anais... Rio de Janeiro: ANPAD, 2011. p. 1-16. Disponível em: <http://www.anpad.org.br/admin/pdf/EOR2782.pdf>. Acesso em: maio 2017.

RISTOFF, Dilvo. A trajetória da mulher na educação brasileira. Brasília, DF: Ministério da Educação, 2006. 
SANTOMÉ, Jurjo Torres. El curriculum oculto. 4. ed. Madrid: Morata, 1994.

SAVIANI, Dermeval. Entrevista. Informando do PPGE, São Carlos, n. 5, p. 2-6, jun.jjul. 2001. Número Especial de Aniversário do Programa.

SAVIANI, Dermeval; GOLDBERG, Maria Amélia Azevêdo. A Universidade Federal de São Carlos (UFSCar): mais um programa de pós-graduação em educação? Cadernos de Pesquisa, São Paulo, n. 16 , p. 81-89, mar. 1976.

SILVA, Tomaz Tadeu da. 0 que produz e o que reproduz em educação. Porto Alegre: Artmed, 1992.

THIRY-CHERQUES, Hermano Roberto. Pierre Bourdieu: a teoria na prática. Revista de Administração Pública - RAP, Rio de Janeiro, v. 40, n. 1, p. 27-55, jan./fev. 2006.

WARDE, Mirian. O papel da pesquisa na pós-graduação em educação. Cadernos de Pesquisa, São Paulo, n. 73, p. 67-75, maio 1990.

XAVIER, Libânia Nacif. O Brasil como laboratório: educação e ciências sociais no projeto do Centro Brasileiro de Pesquisas Educacionais. Bragança Paulista: Edusf, 1999. 